\title{
Valve-sparing root replacement for failed pulmonary autografts: Should a David repair a Ross?
}

\author{
Andrew B. Goldstone, MD, and Y. Joseph Woo, MD
}

\author{
From the Department of Cardiothoracic Surgery, Stanford University School of Medicine, Stanford, Calif. \\ Disclosures: Authors have nothing to disclose with regard to commercial support. \\ Received for publication Sept 2, 2015; accepted for publication Sept 3, 2015. \\ Address for reprints: Y. Joseph Woo, MD, Norman E. Shumway Professor and Chair, Department of Cardiotho- \\ racic Surgery, Professor by courtesy, Department of Bioengineering, Stanford University, Falk Building \\ CV-235, 300 Pasteur Dr, Stanford, CA 94305-5407 (E-mail: joswoo@stanford.edu). \\ J Thorac Cardiovasc Surg 2015;150:1138-9 \\ $0022-5223 / \$ 36.00$ \\ Copyright (c) 2015 by The American Association for Thoracic Surgery \\ http://dx.doi.org/10.1016/j.jtcvs.2015.09.016
}

Mechanical and bioprosthetic prostheses are limited by their significant thromboembolic risk and questionable durability, respectively, when implanted in younger individuals. An ideal substitute for the aortic valve would demonstrate excellent hemodynamics, avoid the need for long-term anticoagulation, reduce infectious risk, and grow with the recipient. The pulmonary autograft was used to meet most of these characteristics, but the tradeoff was a more technically demanding operation. ${ }^{1}$ Although the Ross procedure has its merits, in reality there is no perfect replacement for the native aortic valve. In fact, greater perioperative risk coupled with a real risk of reoperation has recently made many surgeons rethink the utility of the Ross procedure. ${ }^{2}$ Because the Ross procedure is typically reserved for younger patients, when the autograft fails, the early risk versus late benefit discussion must be revisited, particularly if considering salvaging a failed autograft.

In this issue of the Journal, Mookhoek and colleagues ${ }^{3}$ describe the European multicenter experience with valvesparing reoperations after the Ross procedure. Mookhoek and colleagues ${ }^{3}$ should be congratulated on their results; their technical expertise is clearly evidenced by their superlative outcomes. An operative mortality of $1.2 \%$ in the setting of a reoperative aortic root is truly exemplary. It is, however, surprising that this operative mortality is lower than that of the index Ross procedure, which typically carries an operative mortality between $2 \%$ and $3 \%$. $^{4-6}$ Despite longer operative times and nearly 1 in 5 patients undergoing concomitant replacement of the pulmonary outflow graft, the operative mortality achieved by Mookhoek and colleagues ${ }^{3}$ falls within the range that the Society of Thoracic Surgeons risk calculator predicts for a reoperative aortic valve replacement $(0.8 \%-1.2 \%)$ in patients with average characteristics of the study population (for male patients, 38 year old, normal ventricular function, predicted operative mortality is $0.8 \%$; for female patients, 38 year old, left ventricular ejection fraction, predicted operative mortality is $50 \%-1.2 \%$ ). Therefore, unlike that of the index Ross procedure, early risk of autograft valvelimitation. (Figure 1). ${ }^{7-9}$

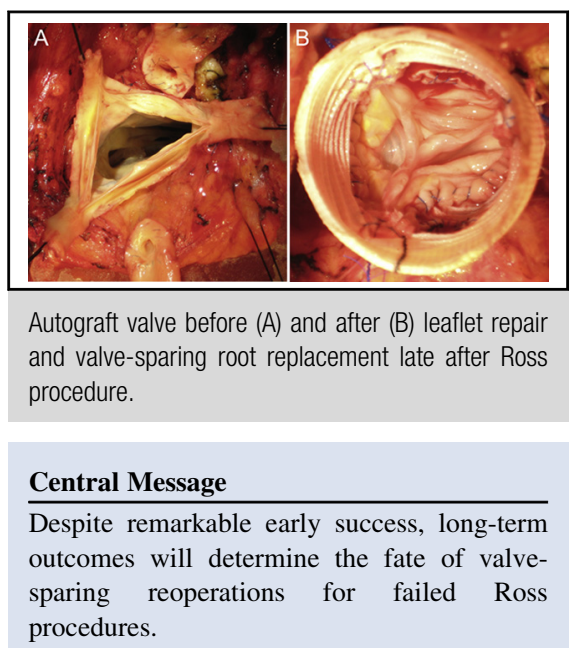

See Article page 1132 .

sparing reoperation does not seem to be a significant

Salvaging a valve to avoid long-term anticoagulation at the expense of a marginally increased operative risk is acceptable only if that valve remains durable from reoperation. Reconstruction may also require repair of the autograft leaflets. ${ }^{7}$ Unfortunately, rates of reoperation for failure of the valve-sparing reoperation in the current study are far from negligible. Nearly $25 \%$ of patients required a reoperation within 8 years of their valve-sparing operation. Mookhoek and colleagues ${ }^{3}$ note that those at the greatest risk for failure of the valve-sparing reoperation were those with isolated or severe aortic regurgitation, as well as those who did not undergo a full root procedure for their index surgery. When the analysis was limited to those who underwent the full root procedures, however, 8-year freedom from reoperation was $85 \%$. Although it is not evident in the study of Mookhoek and colleagues, ${ }^{3}$ the exact variant of the valve-sparing root replacement likely impacts durability. As such, we favor the reimplantation technique in all scenarios, regardless of complexity, as well as robust leaflet repair as demonstrated in our patient undergoing valve-sparing root replacement after a Ross procedure

True of most surgical procedures, selection bias is paramount in evaluating outcomes. Missing from the article by Mookhoek and colleagues ${ }^{3}$ is an explanation of why 110 patients who underwent autograft reoperation after a failed Ross procedure were not selected for a valve-sparing 

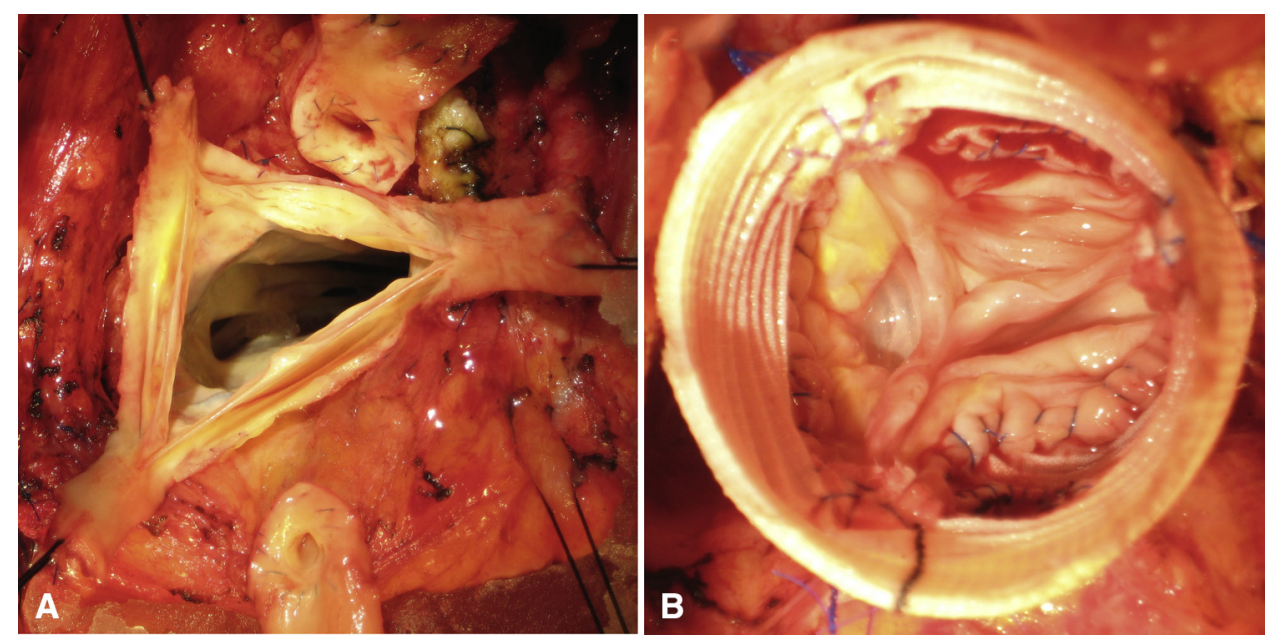

FIGURE 1. Autograft valve before (A) and after (B) leaflet repair and valve-sparing root replacement late after Ross procedure.

operation. An understanding of the reasons for treatment allocation provides insight into additional patient or anatomic characteristics that preclude a safe, successful valve-sparing reoperation.

Lacking a perfect substitute for the aortic valve in the young adult, surgeons must weigh the risks and benefits of each therapy in a probabilistic manner, as well as respect patient preferences and social circumstances. Choosing the Ross procedure as an index operation is a difficult decision in and of itself ${ }^{10}$; choosing to spare the autograft valve after failure of the Ross repair is equally, if not more, difficult. The patient who undergoes a successful, durable valvesparing reoperation will benefit greatly from this anticoagulant-free option. The patient who requires yet another reoperation for the autograft failing-not once, but twice-has certainly suffered. Mookhoek and colleagues ${ }^{3}$ should be complimented for providing the hard data to add real numbers to this complex risk-benefit equation. Although more long-term data are needed before autograft valve-sparing reoperations can be considered routine, it is clear that this operation can be performed safely in specific populations.

\section{References}

1. Ross DN. Replacement of aortic and mitral valves with a pulmonary autograft. Lancet. 1967;2:956-8.

2. Reece TB, Welke KF, O’Brien S, Grau-Sepulveda MV, Grover FL, Gammie JS Rethinking the Ross procedure in adults. Ann Thorac Surg. 2014;97:175-81.

3. Mookhoek A, de Kerchove L, El Khoury G, Weimar T, Luciani GB, Mazzucco A, et al. European multicenter experience with valve-sparing reoperations after the Ross procedure. J Thorac Cardiovasc Surg. 2015;150:1132-7.

4. Mastrobuoni S, de Kerchove L, Solari S, Astarci P, Poncelet A, Noirhomme P, et al. The Ross procedure in young adults: over 20 years of experience in our Institution. Eur J Cardiothorac Surg. March 3, 2015 [Epub ahead of print].

5. Miskovic A, Monsefi N, Karimian-Tabrizi A, Zierer A, Moritz A. A 17-year, single-centre experience with the Ross procedure: fulfilling the promise of a durable option without anticoagulation? Eur J Cardiothorac Surg. March 8, 2015 [Epub ahead of print].

6. Takkenberg JJ, Klieverik LM, Schoof PH, van Suylen RJ, van Herwerden LA, Zondervan PE, et al. The Ross procedure: a systematic review and meta-analysis. Circulation. 2009;119:222-8.

7. Goldstone AB, Woo YJ. Pulmonary autograft leaflet repair and valve sparing root replacement to correct late failure of the Ross procedure. J Card Surg. 2013;28: 496-9.

8. Kaczorowski DJ, Woo YJ. Valve-sparing aortic root replacement with translocation of anomalous left coronary artery. Ann Thorac Surg. 2013;96:1466-9.

9. Woo YJ, Frederick JR. Valve-sparing aortic root replacement and neochordal repair of complex aortic leaflet pathology for ruptured sinus of Valsalva aneurysm fistulizing to the right ventricle. Ann Thorac Surg. 2013;96:1891-3.

10. Sundt TM. Early risk; late reward? Eur J Cardiothorac Surg. March 15, 2015 [Epub ahead of print]. 